\title{
Pair housing and enhanced milk allowance increase play behavior and improve performance in dairy calves
}

\author{
M. B. Jensen, ${ }^{* 1}$ L. R. Duve, ${ }^{*}$ and D. M. Weary $†$ \\ *Department of Animal Science, Aarhus University, Blichers Allé 20, PO Box 50, DK-8830 Tjele, Denmark \\ †Animal Welfare Program, University of British Columbia, 2357 Main Mall, Vancouver, BC, V6T 1Z4, Canada
}

\begin{abstract}
To investigate the effects of social housing and milk feeding on play behavior and performance, 48 HolsteinFriesian male and female calves were either individually or pair housed in straw-bedded pens $(3.0 \mathrm{~m} \times 4.5 \mathrm{~m})$. Half of the calves in each housing treatment were fed a standard milk allowance ( $5 \mathrm{~L} / \mathrm{d}$ from d 3 to 42 ); the other calves were fed an enhanced milk allowance $(9$ $\mathrm{L} / \mathrm{d}$ from d 3 to 28 and $5 \mathrm{~L} / \mathrm{d}$ from d 29 to 42 ). All calves were abruptly weaned on d 43. Play behavior was recorded for $48 \mathrm{~h}$ beginning on d 15, 29, and 43 . Variables were square root-transformed before analysis, but back-transformed values are given. On d 15 the duration of locomotor play behavior was greater among enhanced- than standard-fed calves $[15.2$ vs. $10.8( \pm 1.0)$ corresponding to 231 vs. $117 \mathrm{~s} / 24 \mathrm{~h}]$; this behavior decreased when milk allowance in the enhanced treatment was reduced on d 29. Across ages, the duration of locomotor play behavior was greater among individually housed than pair-housed calves [10.9 vs. $8.2( \pm 0.6)$ corresponding to 119 vs. $67 \mathrm{~s} / 24 \mathrm{~h}$ ], but the total duration of play did not differ between individual and pair-housed calves [130 (45-295) s/24 h; median and interquartile range]. Only pair-housed calves could perform social play behavior (play fighting), and the duration of this was greater on d 15 and 29 than on d $43[8.3,10.7$ and $3.5( \pm 1.3)$ corresponding to 69,115 and $12 \mathrm{~s} / 24 \mathrm{~h}$ for $\mathrm{d} 15,29$, and 43]. Among calves on enhanced milk, pair-housed animals had a greater concentrate intake than individually housed calves (840 vs. $530 \pm 110 \mathrm{~g} / \mathrm{d}$ ); for calves on standard milk, we detected no effect of housing [990 and 1,090 $( \pm 110) \mathrm{g} / \mathrm{d}]$. Among calves on enhanced milk, pair-housed calves had greater body weight gain than individually housed calves [990 vs. $850( \pm 40)$ g/d]. For calves on standard milk, we observed no effect of pair versus individual housing [810 and $840( \pm 40) \mathrm{g} / \mathrm{d}]$. In conclusion, greater durations of play behavior in enhanced-fed calves sug-
\end{abstract}

Received April 23, 2014.

Accepted November 23, 2014.

${ }^{1}$ Corresponding author: MargitBak.Jensen@agrsci.dk gest an animal welfare benefit of this feeding method. Enhanced-fed calves consumed less concentrate, but pair housing stimulated concentrate intake in these calves, suggesting that pair housing and enhanced feeding should be used together.

Key words: welfare, group housing, milk feeding, play behavior, performance

\section{INTRODUCTION}

During the first weeks of life, dairy calves are typically kept in individual housing and fed limited quantities of milk. Recent research has begun to question these practices. For example, when calves are housed in pairs or small groups, they perform more social behaviors (Duve and Jensen, 2012) and form social bonds (Færevik et al., 2006; Raussi et al., 2010; Duve and Jensen, 2011). Socially housed calves also vocalize less than individually housed calves when they are weaned (De Paula Vieira et al., 2010) and struggle less when subjected to handling and blood sampling (Duve et al., 2012), suggesting that the presence of a peer provides a buffer during stressful management procedures.

There is also growing evidence that feeding more milk benefits calf welfare. Ad libitum whole-milk intakes of Holstein calves are $10 \mathrm{~L} / \mathrm{d}$ or more (Appleby et al., 2001; Jasper and Weary, 2002). In contrast, calves offered the traditional allowance of approximately 5 L/d of whole milk (Thomas et al., 2001; De Paula Vieira et al., 2008) or replacer (Jensen and Holm, 2003; Nielsen et al., 2008) show behavioral signs of hunger such as unrewarded milk feeder visits and vocalization. Undernourishment and hunger adversely affect animal welfare and may prevent the animals from experiencing positive states (Špinka et al., 2001; Boissy et al., 2007). For instance, Krachun et al. (2010) found that the duration of locomotor play behavior in preweaned dairy calves was greater in calves fed $12 \mathrm{~L} / \mathrm{d}$ of whole milk compared with calves fed $6 \mathrm{~L} / \mathrm{d}$ and suggested that locomotor play behavior is a useful measure of how the welfare of calves is affected by feeding practices. Play behavior in dairy calves includes both social play and locomotor play. Locomotor play behavior consists 
of galloping with sudden change of direction, bucking, hind leg kicking, and body and head rotations and twists. The behavior includes elements of defense and flight but when performed as play, these elements are exaggerated, repeated, and more variable than during the corresponding functional behavior. Social play consists of interactions resembling those during aggressive interactions but when performed as play they do not result in flight or submission, and social play is typically interspersed with locomotor play and rotations of the head directed toward the play partner (Jensen et al., 1998). How feeding practices affect social play has not been investigated and it is unknown if both categories of play behavior are affected by energy intake and whether social housing results in more play regardless of milk allowance. The first aim of the present study was to investigate these 2 questions.

Young calves are unable to compensate for a low milk intake by increasing their concentrate intake during the first weeks of life (Khan et al., 2011) and although calves fed low quantities of milk ingest more concentrates, they have markedly lower nutrient intakes and BW daily gains compared with calves offered higher milk allowances (Jasper and Weary, 2002; Jensen, 2006; Khan et al., 2007). Eventually, all calves must make the transition from milk to solid feed, and weaning from milk causes less of a distress response and growth check if animals are well established on solid feed before the milk is withdrawn. De Paula Vieira et al. (2010) found that pair-housed calves had greater intakes of concentrates than individually housed calves before weaning, an effect likely due to social facilitation of feeding. Therefore, we might expect a larger effect of pair housing for the enhanced-fed calves. The second aim of the present study was to investigate the interactive effects of pair housing and enhanced milk feeding on concentrate intake and BW gain.

\section{MATERIALS AND METHODS}

The study took place at Aarhus University's cattle research facilities in Foulum, Denmark. Animals were cared for and treated according to a protocol approved by the Danish Animal Experiments Inspectorate, The Danish Ministry of Justice, Copenhagen, Denmark.

\section{Animals and Treatments}

Forty-eight Holstein-Friesian male and female calves were allocated to 8 blocks of 6 calves. In each block the 6 calves were allocated to 1 of 4 treatments: individually housed and fed a standard milk allowance (IS; 5 L/d from d 3 to $42 ; 1$ calf/block); individually housed and fed an enhanced milk allowance (IE; 9 L/d from d
3 to 28 and $5 \mathrm{~L} / \mathrm{d}$ from d 29 to $42 ; 1$ calf/block); pair housed and fed the standard milk allowance (PS; 2 calves/block); or pair housed and fed the enhanced milk allowance (PE; 2 calves/block). The ratios of male to female calves in each treatment group were 6:2, 4:4, 7:9, and 7:9 for IS, IE, PS, and PE, respectively. The mean birth weight of the calves was $43.5 \pm 5.7 \mathrm{~kg}$ (mean \pm $\mathrm{SD}$ ). The mean age difference of the calves within a block was $5 \pm 2$ d. To reduce disturbance in the barn, all management procedures (except colostrum feeding) were performed according to the age of the youngest calf in the block.

\section{Housing}

All calves were born in individual maternity pens in a calving facility less than $100 \mathrm{~m}$ from the calf barn. Individually housed calves and the youngest calves of a pair were moved to the calf barn within 6 to $8 \mathrm{~h}$ of birth, whereas the oldest calves of a pair (treatments PS and $\mathrm{PE}$ ) were kept in an individual pen placed in a separate room in the calving facility until the youngest calf of the pair was born. All calves were moved to the calf barn in a cart; pair-housed calves were moved together, whereas individually housed calves were moved alone.

The straw-bedded pens $(3.0 \mathrm{~m} \times 4.5 \mathrm{~m})$ in the calf barn had sides made of vertical metal bars. Adjacent pens were positioned $1.5 \mathrm{~m}$ apart, preventing physical contact between calves in different pens. Within the block, position of each treatment in the barn was randomized. All calves were fed $4 \mathrm{~L}$ of the dam's colostrum within $6 \mathrm{~h}$ of birth. Over the next $3 \mathrm{~d}$, they were fed $3 \mathrm{~L}$ of fresh colostrum twice a day $(0700$ and $1500 \mathrm{~h})$ from a colostrum pool, and from d 4 they were fed fresh whole milk. Calves on the standard allowance received $2.5 \mathrm{~L}$ of milk per feeding (i.e., $5 \mathrm{~L} / \mathrm{d}$ ) and calves on the enhanced allowance received $4.5 \mathrm{~L}$ of milk per feeding (i.e., $9 \mathrm{~L} / \mathrm{d}$ ) until the youngest calf in the block was 28 d old. From d 29, all calves received $2.5 \mathrm{~L}$ of milk per feeding until they were abruptly weaned off milk on $\mathrm{d}$ 43 (day of age referring to the age of youngest calf in the block). All milk feedings were offered in teat buckets (plastic buckets fitted with one teat; Peach Teat, Skellerup Industries Ltd., Christchurch, New Zealand). All buckets were individually marked and cleaned between feedings. Calves had free access to water, concentrate (18\% CP, 4\% fat, and 6\% fiber; Gron Kalv Valset; DLG, Copenhagen, Denmark), and hay throughout the study. Fresh straw bedding was supplied on a regular basis and pens were cleaned out every $14 \mathrm{~d}$. Artificial lights were on in the barn from 0600 to $2200 \mathrm{~h}$ and were dimmed throughout the night. The temperature and humidity fluctuated according to overall weather conditions $\left(9.2 \pm 4.6^{\circ} \mathrm{C}\right.$ and $74.8 \pm 7.0 \%$ relative humidity). 
As part of another study, the calves were subjected to weekly blood sampling and behavioral tests from wk 1 to 6 , and play behavior was recorded during the 20 min immediately following the provision of fresh straw bedding on a fixed weekday from wk 2 to 6 . This is described in Duve et al. (2012) and is not part of the present study. The present study only includes undisturbed behavioral observations that were conducted on days without any blood sampling or behavioral testing.

Behavior. A digital camera placed above each pen monitored the behavior of the calves (TVCCD-140IR, Monacor, Bremen, Germany). Behavior was recorded during $48 \mathrm{~h}$ beginning when the youngest calf in the block was 15, 29, and $43 \mathrm{~d}$ old using focal animal sampling and continuous recording (Martin and Bateson, 2007). The recorded behaviors were lying (body rested on sternum or side while the head may be either rested or raised), upright (body supported by legs, standing or moving), locomotor play behavior (including gallop, leap, jump, buck, buck-kick, turn, and head-shake), and straw play behavior (butting or rubbing head in straw). For detailed description of these play behaviors, see Jensen et al. (1998). Among pair-housed calves, social play behavior (play fighting: butting the head against the other calf's' head or neck while the 2 are standing front to front; Jensen et al., 1998) was recorded. It was also noted whether locomotor play behavior was performed solitary or at the same time as the pair-partner was performing locomotor play (parallel locomotor play behavior; Jensen and Kyhn, 2000).

Concentrate Intake. Concentrate intake was recorded per pen starting when the youngest calf in a block was $21 \mathrm{~d}$ old. Daily concentrate intake was measured $4 \mathrm{~d}$ per week (Monday, Tuesday, Wednesday, and Thursday) until $2 \mathrm{~d}$ after the calves were weaned (d 45 referring to the age of the youngest calf in the block).

$\boldsymbol{B} \boldsymbol{W}$. Calves were weighed within $6 \mathrm{~h}$ of birth, and on a fixed weekday when the youngest calf in a block was 16,30 , and $44 \mathrm{~d}$ old. When the youngest calf in a block was $44 \mathrm{~d}$ old, the average age of the calves was $47 \pm 2$ $\mathrm{d}($ mean $\pm \mathrm{SD})$.

\section{Statistical Analysis}

For each calf and 48-h observation period, the average duration of lying, locomotor play behavior, and straw play behavior per $24 \mathrm{~h}$ was calculated. Average duration of all play behavior (the sum of locomotor, social, and straw play) was calculated for each calf. Within observation period, these data were averaged for each pair of pair-housed calves, yielding one data point per pen per observation period (age). Due to many zero observations, the variable straw play behavior was transformed into a binary variable (i.e., presence or absence of this type of play within the observational period). The duration of social play behavior and the duration of parallel locomotor play per $24 \mathrm{~h}$ among pair-housed calves were calculated for each pair of pair-housed calves, yielding one data point per pen per observation period. The proportion of locomotor play performed as parallel locomotor play was also calculated. The duration of lying, the duration of locomotor play behavior, and the duration of all play behavior were analyzed using a linear mixed model including the fixed effects of social contact (individual or pairhoused), milk allowance (standard or enhanced), and age (d 15, 29, and 43), as well as all interactions. Block was included as a random effect, repeated observations on the same pen were modeled as autoregressive of first order, and Satterthwaite's approximation was used to estimate the denominator degrees of freedom. The duration of social play behavior and the proportion of parallel locomotor play among calves in pair-pens were analyzed using a similar model. The duration of locomotor play behavior and the duration of social play behavior were skewed and these variables were square root-transformed before analysis to meet the assumption of normal distribution. The sex of the calf (or pair of calves) was included in initial models, but was not significant for any of the variables $(P>0.15)$ and was therefore excluded from the final models. Chi-squared test was used to analyze the effect of social contact and milk allowance on whether or not straw play behavior was observed in the pen.

Daily concentrate intake was calculated for each pen and an average per calf was calculated for each pen of pair-housed calves. An average daily concentrate intake per calf (pen being the statistical unit) was then calculated over the period from d 21 to 43 . These data were analyzed using a linear model including the fixed effects of social contact (individual or pair housed), milk allowance (standard or enhanced), sex (male, female, or mixed sex pair), and the interaction between social contact and milk allowance.

Daily BW gains of individual calves from birth to $\mathrm{d}$ 16, from d 16 to 30, and from d 30 to 44 (all days of age referring to the age of youngest calf in the block) were calculated and then averaged for each pen of pairhoused calves. These data were analyzed using a linear mixed model including the fixed effects of social contact (individual or pair-housed), milk allowance (standard or enhanced), sex (male, female, or mixed sex pair), and age (d 1 to 16 , d 16 to 30 , and d 30 to 44 ), as well as all interactions between social contact, milk allowance, and age. Block was included as a random effect, repeated observations on the same pen were modeled 
as autoregressive of first order, and Satterthwaite's approximation was used to estimate the denominator degrees of freedom.

For all analyses, the assumption of normality was assessed through visual inspection of residual plots. The assumption of homogeneous variance was assessed by inspection of scatter plots of residual versus predicted values. All analyses were conducted with the Mixed procedure of SAS (version 9.3, SAS Institute Inc., Cary, $\mathrm{NC})$.

\section{RESULTS}

\section{Behavior}

The duration of all play behavior was greater for calves fed enhanced milk rations on d 15, with no difference between milk allowances on d 29 and d 43 (milk $\times$ age interaction $\mathrm{F}_{2,62}=6.97 ; P=0.002$; Figure $1)$. The duration of locomotor play behavior was also greater for the enhanced-fed calves on d 15, with no difference between the 2 milk allowances on d 29 and d $43\left(\right.$ milk $\times$ age interaction $\mathrm{F}_{2,60}=4.42 ; P=0.02$; Figure 2). Across ages, the duration of locomotor play behavior was greater among individually housed calves than pair-housed calves $\left[10.9\right.$ vs. $8.2( \pm 0.6) ; \mathrm{F}_{1,30}=$ $10.81 ; P=0.003$; back-transformed means:119 vs. 67 $\mathrm{s} / 24 \mathrm{~h}$. Only pair-housed calves had the opportunity to perform social play. Among pair-housed calves, the duration of social play was lower on d 43 compared with d 15 and 29 [8.3, 10.7 and $3.5( \pm 1.3)$ for d 15, 29 and $43 ; \mathrm{F}_{2,28}=9.32, P<0.001$; back transformed means: $69,115$ and $12 \mathrm{~s} / 24 \mathrm{~h}]$. Furthermore, the proportion of locomotor play behavior that was performed as parallel locomotor play was lower on d 43 compared with the first 2 observation times [transformed proportions:0.46, 0.44 and $0.25( \pm 0.06)$ for $\mathrm{d} 15,29$ and 43 , respectively; $\mathrm{F}_{2.28}=5.76, P<0.01$; back-transformed mean proportions: $0.21,0.19$ and 0.06$]$. On d 15, straw play occurred in more pens with calves fed enhanced milk (5/16 vs. $14 / 16$ for standard and enhanced milk; $\chi_{1}=10.49$; $P<0.001)$. No effect of milk allowance was found in the remaining ages, and no effect of social contact was found at any age. Straw play behavior was observed in more pens on d 29 than on d 15 and $43(19 / 32,27 / 32$, and $11 / 32$ for $\mathrm{d} 15,29$, and $\left.43 ; \chi_{2}=16.58 ; P<0.001\right)$.

\section{Performance}

Among calves on enhanced milk, pair-housed animals had greater concentrate intakes than calves that were individually housed; for calves on standard milk, we detected no effect of social housing (milk allowance $x$ social contact interaction; $\mathrm{F}_{1,26}=4.60 ; P=0.04$; Table

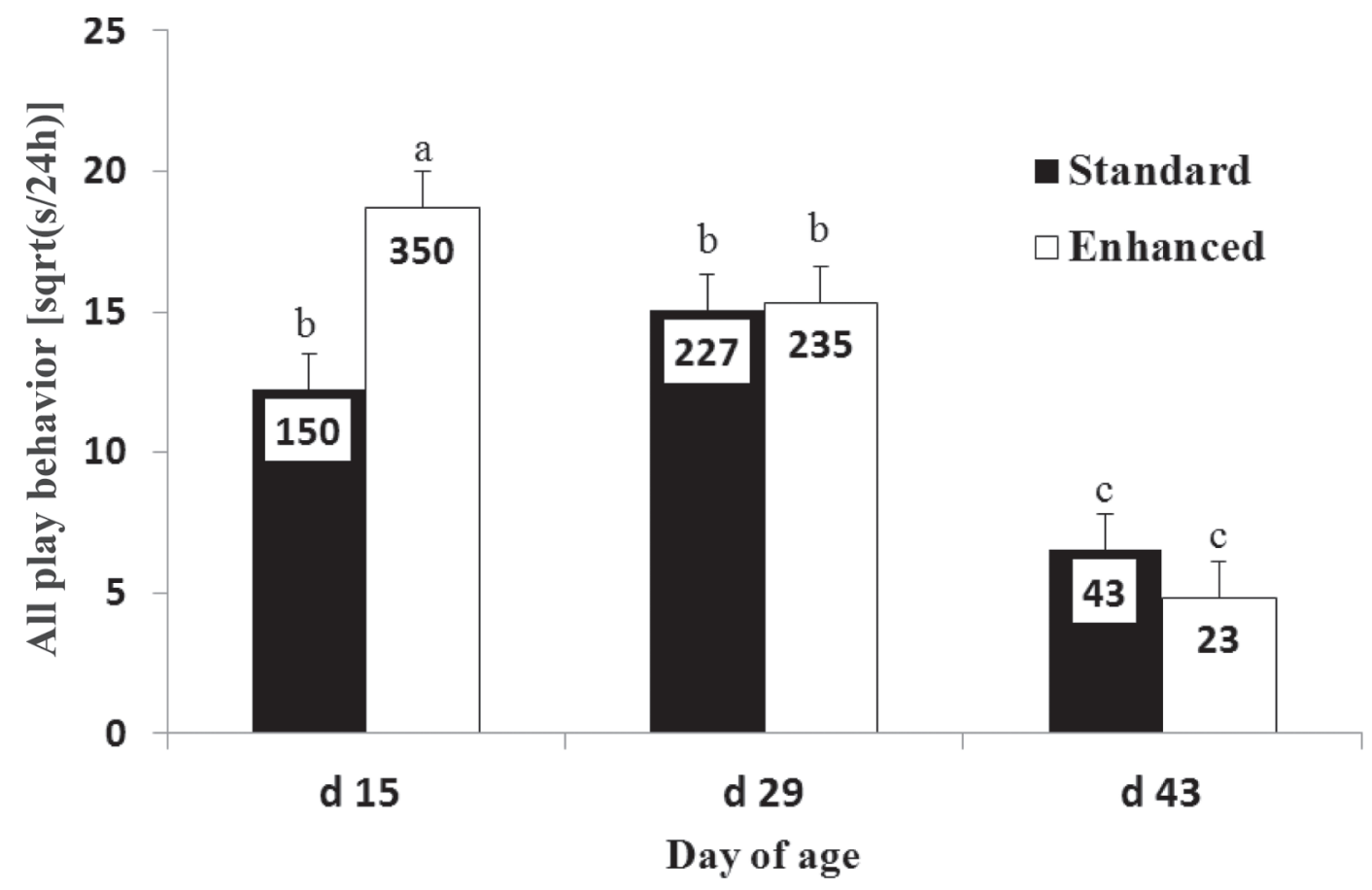

Figure 1. The duration of all play behavior (means \pm SEM) in calves $(\mathrm{n}=48)$ fed either standard $(5 \mathrm{~L} / \mathrm{d}$; black bars $)$ or enhanced milk rations $(9 \mathrm{~L} / \mathrm{d}$, reducing to $5 \mathrm{~L} / \mathrm{d}$ at age $\mathrm{d} 29$; white bars) on d 15, 29, and 43. Data were square root-transformed before analysis, and the back-transformed mean is given within each bar. Bars with different letters $(\mathrm{a}, \mathrm{b})$ are significantly different $(P<0.05)$. 


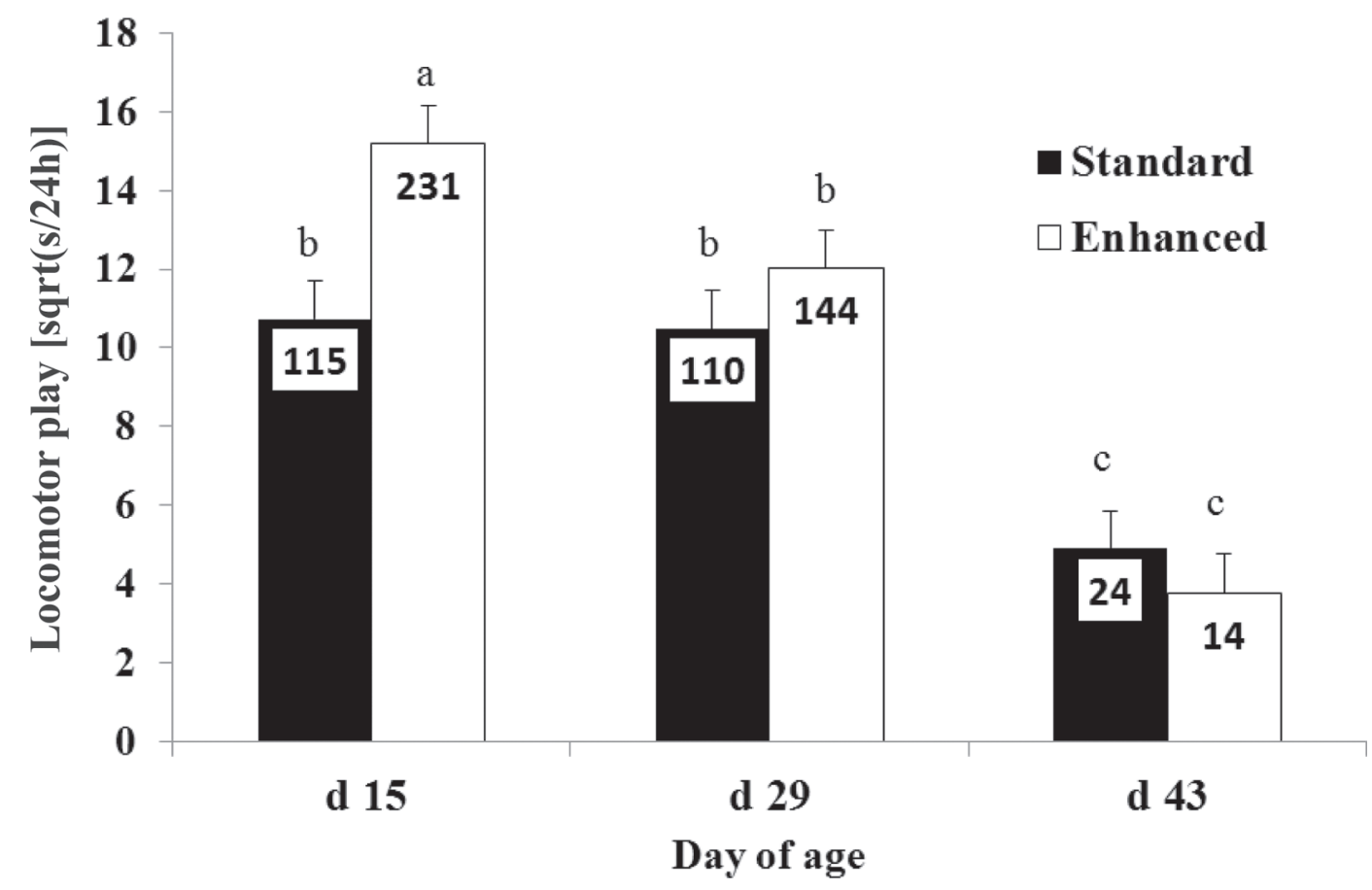

Figure 2. The duration of locomotor play behavior (means \pm SEM) in calves $(n=48)$ fed either standard $(5 \mathrm{~L} / \mathrm{d}$; black bars) or enhanced milk rations $(9 \mathrm{~L} / \mathrm{d}$, reducing to $5 \mathrm{~L} / \mathrm{d}$ at age $\mathrm{d} 29$; white bars) on d 15,29 , and 43 . Data were square root-transformed before analysis, and the back-transformed mean is given within each bar. Bars with different letters (a, b) are significantly different $(P<0.05)$.

1). We noted a similar interaction between milk allowance and social contact for $\mathrm{BW}$ gain $\left(\mathrm{F}_{1,26}=5.35 ; \mathrm{P}\right.$ $=0.03 ;$ Table 1$)$ with pair-housed calves on enhanced milk having greater BW gains than all other calves. For BW gain, we also found an interaction between milk allowance and age [537, 939, 1,000, 1,045, 941, 778 $( \pm 44) \mathrm{g} / \mathrm{d}$ for standard d 1 to 16 , standard d 16 to 30 , standard d 30 to 44 , enhanced d 1 to 16 , enhanced d 16 to 30 , and enhanced d 30 to 44 , respectively; $\mathrm{F}_{2,58}=$ 36.09; $P<0.001]$. From d 1 to 16, calves on enhanced milk gained the most BW; from d 16 to 30, no difference was seen; and from d 30 to 44, standard-fed calves gained more BW. The estimates for the nonsignificant milk allowance $\times$ social contact $\times$ age interaction are shown in Figure 3. We detected an effect of calf sex on BW gain, with males gaining more weight than females and mixed sex pairs showing intermediate gains [960,
850 , and $810( \pm 40) \mathrm{g} / \mathrm{d}$ for males, mixed sex pairs, and females; $\mathrm{F}_{2,58}=4.50 ; P=0.02$ ].

\section{DISCUSSION}

Enhanced milk feeding resulted in more locomotor play behavior than the standard milk allowance, and this play declined when milk allowance was reduced from enhanced to standard levels. Individually housed calves performed more locomotor play than pair-housed calves but, because pair-housed calves also performed social play, the sum of all play behavior did not differ between individually and pair-housed calves. Pair housing stimulated concentrate intake among enhanced milk fed calves and resulted in a greater average daily $\mathrm{BW}$ gain in these calves.

Table 1. Concentrate intake from d 21 to 43 and BW gain from d 1 to 44 of calves $(\mathrm{n}=48)$ fed either standard $(5 \mathrm{~L} / \mathrm{d})$ or enhanced milk rations $(9 \mathrm{~L} / \mathrm{d}$, reducing to $5 \mathrm{~L} / \mathrm{d}$ at age $\mathrm{d} 29)$ and housed either individually or in pairs

\begin{tabular}{lcccccc}
\hline & \multicolumn{2}{c}{ Standard } & & \multicolumn{2}{c}{ Enhanced } & \\
\cline { 2 - 3 } \cline { 5 - 6 } Item & Individual & Pair & & Individual & Pair & SEM \\
\hline Concentrate intake $(\mathrm{g} / \mathrm{d})$ & $1,090^{\mathrm{a}}$ & $990^{\mathrm{a}}$ & & $530^{\mathrm{b}}$ & $840^{\mathrm{a}}$ & 110 \\
BW gain $(\mathrm{g} / \mathrm{d})$ & $840^{\mathrm{b}}$ & $810^{\mathrm{b}}$ & & $850^{\mathrm{b}}$ & $990^{\mathrm{a}}$ & 40 \\
\hline
\end{tabular}

${ }_{\mathrm{a}, \mathrm{b}}$ Means within a row with different superscripts differ $(P<0.05)$. 


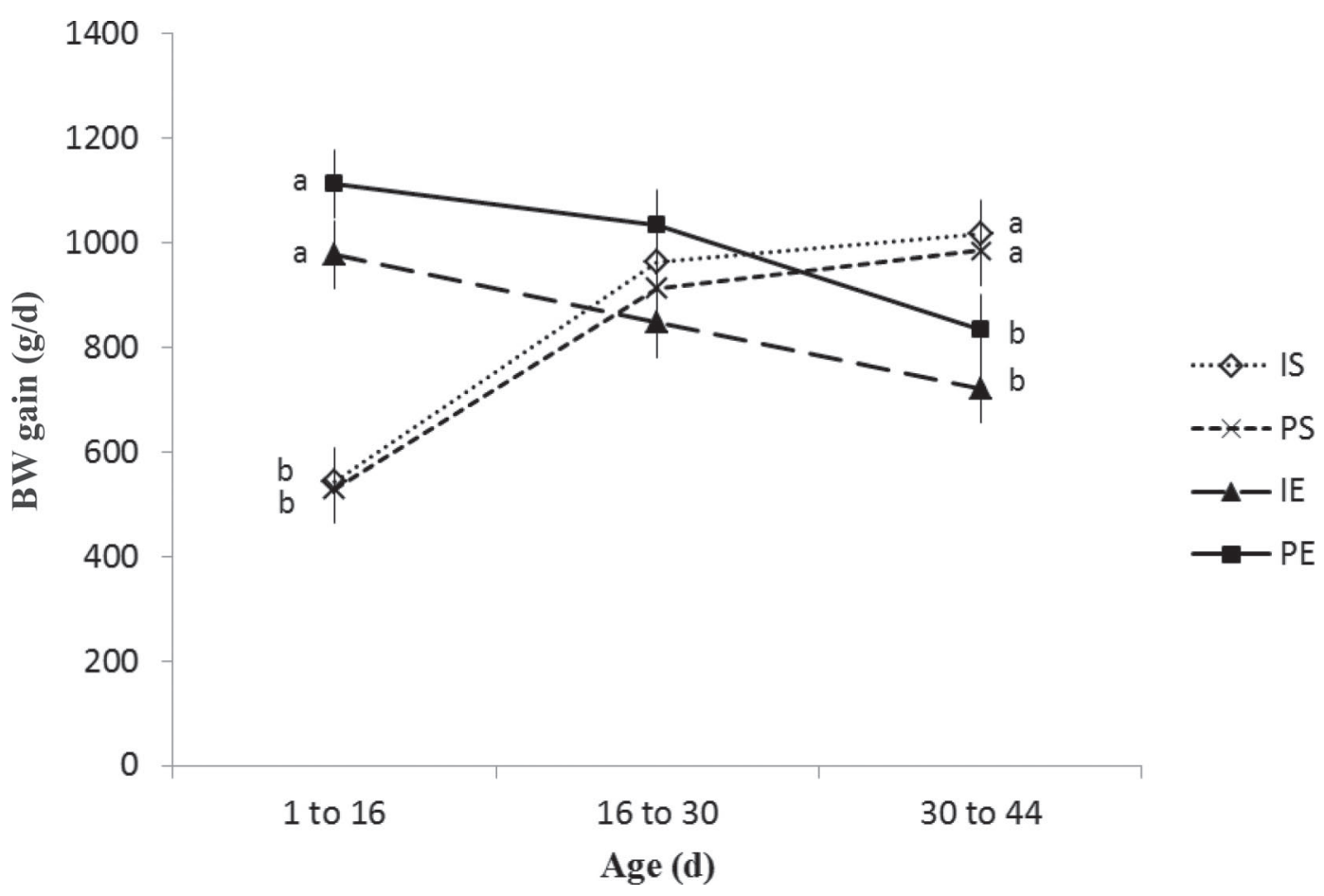

Figure 3. Body weight gain (mean \pm SEM) of calves $(\mathrm{n}=48)$ on treatments IS (individually housed and fed standard milk ration: $5 \mathrm{~L} / \mathrm{d}$ from d 3 to 42), IE (individually housed and fed enhanced milk ration: $9 \mathrm{~L} / \mathrm{d}$ from d 3 to 28 and $5 \mathrm{~L} / \mathrm{d}$ from d 29 to 42 ), PS (pair housed and fed standard milk ration), or PE (pair housed and fed enhanced milk ration) from d 1 to 16, d 16 to 30 , and d 30 to 44 of age. For each age, different letters $(\mathrm{a}, \mathrm{b})$ indicate significant differences $(P<0.05)$ between treatments at that age.

\section{Effect of Enhanced Milk on Play Behavior}

Enhanced-fed calves received $9 \mathrm{~L} / \mathrm{d}$ of whole milk for the first $28 \mathrm{~d}$ and, when observed on $\mathrm{d} 15$, these calves played more than standard-fed calves $(5 \mathrm{~L} / \mathrm{d})$. This supports previous findings of Krachun et al. (2010), in which calves fed $12 \mathrm{~L} / \mathrm{d}$ of whole milk performed more locomotor play behavior compared with calves fed 6 L/d. Furthermore, the abrupt reduction in milk from 9 to $5 \mathrm{~L} / \mathrm{d}$ experienced by enhanced-fed calves on $\mathrm{d} 29$ in the present experiment caused a decrease in locomotor play. No difference in locomotor play between these 2 observation times was detected for standard-fed calves (who continued to receive $5 \mathrm{~L} / \mathrm{d}$ ), so we conclude that the decline in locomotor play of enhanced-fed calves reflects the reduction in milk intake rather than an age effect. Krachun et al. (2010) found that gradual weaning resulted in a decrease in play behavior, and Rushen and de Passillé (2012) also found a reduction in locomotor play in calves weaned from milk.

Play behavior relates to welfare in 2 ways. First, animals are motivated to play when their basic needs for food, shelter, and safety are met, so play reflects an absence of negative affective states. Second, the performance of play behavior is believed to be pleasurable, so increased play is indicative of increased positive experiences (Martin and Caro, 1985; Held and Špinka, 2011). A lower motivation to perform locomotor play by standard-fed calves is likely due to hunger and a motivational shift toward conserving energy and searching for milk. Indeed, the rates of appetitive behavior (searching for milk) are higher in calves fed lower amounts of milk, including higher frequencies of unrewarded visits to an automated milk feeder (Jensen, 2006; De Paula Vieira et al., 2008). The decrease in play behavior in enhanced-fed calves when milk was reduced may also be due to this motivational shift. In the present experiment, calves on both milk allowances were weaned from milk on d 43 and, at this stage, locomotor play was reduced in both treatments.

Only pair-housed calves had the opportunity to perform social play. Among pair-housed calves, no effect of milk allowance or reduction in milk from d 16 to 29 on social play was found, suggesting that this type of play does not relate to nutritional status in the same way as locomotor play. However, as for locomotor play, a marked decline in social play was observed from d 29 to 43 , when all calves were weaned from milk, suggesting a similar effect of hunger and negative affective states on both types of play behavior. Studies in semi-wild ungulates suggest that social play increases during the first few months of life (Vitale et al., 1986; Gomendio, 
1988), and the decline observed in social play in the present study may be transient due to weaning. In piglets, weaning at 4 wk of age caused a transient decrease in both locomotor and social play (Donaldson et al., 2002).

It is unclear whether locomotor play and social play have a shared motivation. Among pair-housed calves, the 2 types of play occurred within the same bout, and locomotor play was often performed in a social context as parallel locomotor play. Individually housed calves may have also played in a social context, but we did not record whether these calves performed locomotor play at the same times as calves in neighboring pens. We encourage future work to specifically address motivation for different types of play and how this is affected by nutritional and health status. A better understanding of the motivation will allow for stronger inferences when using these behaviors as welfare indicators.

\section{Effects of Pair-Housing on Play Behavior}

The home pens of the present study were relatively large to allow the performance of play in the home environment. Jensen and Kyhn (2000) found more play in home pens with 4 calves with 12 to $16 \mathrm{~m}^{2}$ versus 6 to $8 \mathrm{~m}^{2}$, so we assumed that $13.5 \mathrm{~m}^{2}$ for 1 and 2 calves would not restrict locomotor play. The results showed that pair-housed calves performed less locomotor play than did the individually housed calves. This may be because 2 calves in the pens restricted space for locomotor play compared with 1 calf per pen, or it may be because locomotor play replaced social play in individually housed calves. That the sum of all types of play behavior was similar in individual and pair pens supports the latter interpretation. In the present design, pair housing did not result in more play behavior overall, which is accordance with Jensen et al. (1998), who found that space allowance, but not group housing, affected locomotor play behavior.

Episodes of play behavior may be stimulated by provision of novelty or release from the home pen. In another study using the same experimental set-up, Duve et al. (2012) recorded all types of play behavior once weekly during the 20 min immediately following the provision of fresh straw bedding and found that among calves on the standard milk allowance, individually housed calves played less at the age of $3 \mathrm{wk}$. The present study recorded spontaneous play behavior during $48 \mathrm{~h}$ and found that all standard-fed calves played less than enhanced-fed calves at the age of 2 wk. The discrepancy between the 2 measures of play may be because the presence of a social partner increases calves' immediate response to straw provision. However, Mintline et al. (2012) reported a high day-to-day variation in play behavior during 20 min when calves were released in a test area and concluded that caution is required in the interpretation of play episodes during release in an arena. Similarly, short play episodes in response to stimuli provided in the home pen may be variable, and longer continuous observation in the home pens may better reflect calves motivation to play.

\section{Concentrate Intake and BW Gain}

For calves on enhanced milk allowances, pair housing resulted in greater concentrate intakes. This finding agrees with previous work showing that intake of solids (concentrates and forages) was greater among calves kept in small groups versus individually (Babu et al., 2004; Phillips, 2004; Hepola et al., 2006). This positive effect of social housing on intake of solid feed was only observed for the enhanced-fed calves. Calves fed the standard milk allowance were likely to be much hungrier and thus highly motivated to consume any feed accessible regardless of social stimulation. Reduced intake of solid feed is one disadvantage of enhanced milk feeding; the present results indicate that social housing helps overcome this disadvantage.

As expected, milk allowance had a profound effect on BW gain. Better growth was seen in the first $16 \mathrm{~d}$ of life in enhanced-fed calves. This result is consistent with the earlier studies reviewed by Khan et al. (2011). In the present study, BW gains were similar in the next 2 wk of life and slightly lower for the enhanced-fed calves between d 30 and 42 when their milk was reduced, but overall gains were greater in enhanced-fed calves. We have no measures of BW after weaning but previous studies suggest that enhanced-fed calves maintain higher growth rates after weaning (Khan et al., 2007). Dairy calves are traditionally offered a milk allowance of approximately $10 \%$ of $\mathrm{BW}$ per day. Although this is not normally viewed as undernourishment, it is not enough to sustain the calves' growth potential until rumen development allows a substantial intake of solid foods (Bartlett et al., 2006), and a recent review concluded that allotting approximately $20 \% \mathrm{BW}$ per day results in improved health, improved growth, and improved later production (Khan et al., 2011). Increased play behavior in enhanced-fed calves adds to this other evidence in suggesting that higher milk rations provide for increased calf welfare during the milk-feeding period.

\section{CONCLUSIONS}

Calves fed an enhanced allowance of milk early in life performed more locomotor play, suggesting that they experienced improved animal welfare. Enhancedfed calves consumed less concentrate but pair housing 
stimulated concentrate intake in these calves, suggesting that it is advantageous to use pair housing and enhanced milk feeding together.

\section{ACKNOWLEDGMENTS}

The study was funded by the Danish Ministry of Food, Agriculture and Fisheries (Copenhagen, Denmark). The staff members at the cattle facility at Aarhus University, Foulum, are gratefully acknowledged for care of experimental animals. Thanks to John Misa Obidah, Erik Luc Decker (both Aarhus University), and Amélie Mandel (Agrocampus Quest, Rennes, France) for assistance with data collection.

\section{REFERENCES}

Appleby, M. C., D. M. Weary, and B. Chua. 2001. Performance and feeding behaviour of calves on ad libitum milk from artificial teats. Appl. Anim. Behav. Sci. 74:191-201.

Babu, L. K., H. N. Pandey, and A. Sahoo. 2004. Effect of individual versus group rearing on ethological and physiological responses of crossbred calves. Appl. Anim. Behav. Sci. 87:177-191.

Bartlett, K. S., F. K. McKeith, M. J. VandeHaar, G. E. Dahl, and J. K. Drackley. 2006. Growth and body composition of dairy calves fed milk replacers containing different amounts of protein at two feeding rates. J. Anim. Sci. 84:1454-1467.

Boissy, A., G. Manteuffel, M. B. Jensen, R. O. Moe, B. Spruijt, L. J. Keeling, C. Winckler, B. Forkman, I. Dimitrov, and J. Langbein. 2007. Assessment of positive emotions in animals to improve their welfare. Physiol. Behav. 92:375-397.

De Paula Vieira, A., V. Guesdon, A. M. de Passillé, M. A. G. von Keyserlingk, and D. M. Weary. 2008. Behavioural indicators of hunger in dairy calves. Appl. Anim. Behav. Sci. 109:180-189.

De Paula Vieira, A., M. A. G. von Keyserlingk, and D. M. Weary. 2010. Effects of pair versus single housing on performance and behavior of dairy calves before and after weaning from milk. J. Dairy Sci. 93:3079-3085.

Donaldson, T. M., R. C. Newbwerry, M. Spinka, and S. Cloutier. 2002. Effects of play experience on play behaviour of piglets after weaning. Appl. Anim. Behav. Sci. 79:221-231.

Duve, L. R., and M. B. Jensen. 2011. The level of social contact affects social behaviour in pre-weaned dairy calves. Appl. Anim. Behav. Sci. 135:34-43.

Duve, L. R., and M. B. Jensen. 2012. Social behavior of young dairy calves housed with limited or full social contact with a peer. J. Dairy Sci. 95:5936-5945.

Duve, L. R., D. M. Weary, U. Halekoh, and M. B. Jensen. 2012. The effects of social contact and milk allowance on the response to handling, play behavior and social behavior in young dairy calves. J. Dairy Sci. 95:6571-6581.

Færevik, G., M. B. Jensen, and K. E. Bøe. 2006. Dairy calves social preferences and the significance of a companion during separation from the group. Appl. Anim. Behav. Sci. 99:205-221.

Gomendio, M. 1988. The development of different types of play in gazelles: implications for the nature and functions of play. Anim. Behav. 36:825-836.
Held, S. D. E., and M. Špinka. 2011. Animal play and animal welfare. Anim. Behav. 81:891-899.

Hepola, H., L. Hänninen, P. Pursiainen, V.-M. Tuure, L. Syrjälä-Qvist, M. Pyykkönen, and H. Saloniemi. 2006. Feed intake and oral behavior of dairy calves housed individually or in groups in warm or could buildings. Livest. Sci. 105:94-104.

Jasper, J., and D. Weary. 2002. Effects of ad libitum milk intake on dairy calves. J. Dairy Sci. 85:3054-3058.

Jensen, M. B. 2006. Computer-controlled milk feeding of group-housed calves, the effect of milk allowance and weaning type. J. Dairy Sci. 89:201-206.

Jensen, M. B., and L. Holm. 2003. The effect of milk flow rate and milk allowance on feeding related behaviour in dairy calves fed by computer controlled milk feeders. Appl. Anim. Behav. Sci. $82: 87-100$.

Jensen, M. B., and R. Kyhn. 2000. Play behaviour in group-housed dairy calves, the effect of space allowance. Appl. Anim. Behav. Sci. $67: 35-46$.

Jensen, M. B., K. S. Vestergaard, and C. C. Krohn. 1998. Play behaviour in dairy calves kept in pens: The effect of social contact and space allowance. Appl. Anim. Behav. Sci. 56:97-108.

Khan, M. A., H. J. Lee, W. S. Lee, H. S. Kim, S. B. Kim, K. S. Ki, J. K. Ha, H. G. Lee, and Y. J. Choi. 2007. Pre- and postweaning performance of Holstein female calves fed milk through step-down and conventional methods. J. Dairy Sci. 90:876-885.

Khan, M. A., D. M. Weary, and M. A. G. von Keyserlingk. 2011. Invited review: Effects of milk ration on solid feed intake, weaning and performance in dairy heifers. J. Dairy Sci. 94:1071-1081.

Krachun, C., J. Rushen, and A. M. de Passillé. 2010. Play behaviour in dairy calves is reduced by weaning and by a low energy intake. Appl. Anim. Behav. Sci. 122:71-76.

Martin, P., and P. Bateson. 2007. Measuring Behaviour. An Introductory Guide. Cambridge University Press, Cambridge, UK.

Martin, P., and T. M. Caro. 1985. On the functions of play and its role in development. Pages 59-103 in Advances in the Study of Behaviour. J. S. Rosenblatt and P. J. B. Slater. Academic Press, Orlando, FL.

Mintline, E. M., S. L. Wood, A. M. de Passillé, J. Rushen, and C. B. Tucker. 2012. Assessing calf play behavior in an arena test. Appl. Anim. Behav. Sci. 141:101-107.

Nielsen, P. P., M. B. Jensen, and L. Lidfors. 2008. Milk allowance and weaning method affect the use of a computer controlled milk feeder and the development of cross-sucking in dairy calves. Appl. Anim. Behav. Sci. 109:223-237.

Phillips, C. J. C. 2004. The effects of forage provision and group size on the behavior of calves. J. Dairy Sci. 87:1380-1388.

Raussi, S., S. Niskanen, J. Siivonen, L. Hänninen, H. Hepola, L. Jauhiainen, and I. Vieissier. 2010. The formation of preferential relationships at early age in cattle. Behav. Processes 84:726-731.

Rushen, J., and A. M. de Passillé. 2012. Automated measurement of acceleration can detect effects of age, dehorning and weaning on locomotor play of calves. Appl. Anim. Behav. Sci. 139:169-174.

Špinka, M., R. C. Newberry, and M. Bekoff. 2001. Mammalian play: Training for the unexpected. Q. Rev. Biol. 76:141-168.

Thomas, T. J., D. M. Weary, and M. C. Appleby. 2001. Newborn and 5 -week old calves vocalise in response to milk deprivation. Appl. Anim. Behav. Sci. 74:165-173.

Vitale, A. F., M. Tenucci, M. Papini, and S. Lovari. 1986. Social behavior of the calves of semi-wild Maremma cattle, Bos primigenius taurus. Appl. Anim. Behav. Sci. 16:217-231. 